Info Artikel Diterima April 2019

Disetujui Juli 2019

Dipublikasikan Oktober 2019

\title{
ANALISIS USAHA PENGOLAHAN KOPI ROBUSTA \\ DI KECAMATAN GEMBONG KABUPATEN PATI
}

\section{BUSINESS ANALYSIS OF PROCESSING COFFEE ROBUSTA IN GEMBONG DISTRICT PATI REGENCY}

\author{
Riski Anjar Sari *, Shofia Nur Awami , Aniya Widiyani \\ Program Studi Agribisnis \\ Fakultas Pertanian Universitas Wahid Hasyim Semarang \\ *Email: riskianjarsari20@gmail.com
}

\begin{abstract}
Gembong subdistrict is producing coffee area in Pati Regency which is processed into black coffee powder and green coffee powder. This research aims to know the value-added, income and eligibility processing robusta coffee. The basic method of research used descriptive method. Location retrieval methods of research with purposive sampling. Sampling of respondents by the census method, data collection by way of interviews, observation and record-keeping. The data analysis methods are added value, cost, revenue and earnings, and also feasibility analysis BEP and R/C. The results showed there was a difference in the average of ratio value added processing black and green coffe powder they are $43.52 \%$ and $48.06 \%$, the average revenues of coffee powder processing black and green respectively is Rp. 360.592/PP one week and Rp. 580.313/PP one week, the average of breakeven black coffee powder and green coffe powder a value of BEP (Production) $10.90 \mathrm{~kg}$ and $4.91 \mathrm{~kg}$ (the real are $12.48 \mathrm{~kg}$ and $6.84 \mathrm{~kg}$ ), BEP (Price) of Rp. $90.813 / \mathrm{kg}$ and Rp. $154.489 / \mathrm{kg}$ (the real are Rp. 104,000/kg and Rp. 215,000/kg) and BEP (Acceptance) of Rp. 751.431/PP one week and Rp.379.426/PP one week (the real are Rp. 1.297.920/PP one week and Rp.1.470.600/PP one week), and $\mathrm{R} / \mathrm{C}$ value of black dan green coffee powder processing are 1.38 and 1.65 .
\end{abstract}

Keywords: Value Added, Robusta Coffee, Black Coffee, Green Coffee, Gembong

\begin{abstract}
ABSTRAK
Kecamatan Gembong merupakan daerah penghasil kopi di Kabupaten Pati yang diolah menjadi bubuk kopi hitam dan bubuk kopi hijau. Penelitian ini bertujuan untuk mengetahui nilai tambah, pendapatan dan kelayakan usaha pengolahan kopi robusta. Metode dasar penelitian yang digunakan metode deskriptif. Metode pengambilan lokasi penelitian dengan purposive sampling. Pengambilan sampel responden dengan metode sensus, pengumpulan data dengan cara wawancara, observasi dan pencatatan. Metode analisis data yang digunakan adalah analisis nilai tambah, biaya, penerimaan dan pendapatan, dan analisis kelayakan berupa BEP dan R/C. Hasil penelitian menunjukkan terdapat perbedaan rata-rata rasio nilai tambah usaha pengolahan bubuk kopi hitam dan hijau masing-
\end{abstract}


masing 43,52\% dan 48,06\%, rata-rata pendapatan usaha pengolahan bubuk kopi hitam dan hijau masing-masing sebesar Rp. 360.592/PP 1 Minggu dan Rp. 580.313/PP 1 Minggu, rata-rata titik impas pengolahan bubuk kopi hitam dan hijau masing-masing menghasilkan nilai BEP (Produksi) $10,90 \mathrm{~kg}$ dan 4,91 kg (riil $12,48 \mathrm{~kg}$ dan $6,84 \mathrm{~kg}$ ), BEP (Harga) Rp. $90.813 / \mathrm{kg}$ dan Rp. 154.489/kg (riil Rp. 104.000/kg dan Rp. 215.000/kg) dan BEP(Peneriman) Rp. Rp. 751.431/PP 1 Minggu dan Rp. 379.426/PP 1 Minggu (riil Rp. 1.297.920/PP 1 Minggu dan Rp. Rp. 1.470.600/PP 1 Minggu), dan nilai R/C pengolahan bubuk kopi hitam dan hijau masing-masing sebesar 1,38 dan 1,65.

\section{Kata kunci : Nilai Tambah, Kopi Robusta, Kopi Hitam, Kopi Hijau, Gembong}

\section{PENDAHULUAN}

Agroindustri adalah suatu usaha untuk menciptakan suatu produk olahan dalam bentuk barang jadi maupun barang setengah jadi yang bahan baku utamanya merupakan produk pertanian (Soeharjono, 2001). Kegiatan agroindustri dinilai dapat meningkatkan nilai tambah. Nilai tambah yang diperoleh adalah selisih antara nilai komoditas yang mendapat perlakuan pada tahap tertentu dengan nilai pengorbanan yang digunakan selama proses produksi berlangsung Nilai tambah menunjukkan balas jasa untuk modal, tenaga kerja, manajemen perusahaan. Mengingat sifat produk pertanian yang tidak tahan lama maka peran agroindustri sangat diperlukan.

Kopi merupakan salah satu jenis tanaman perkebunan yang sudah lama dibudidayakan dan memiliki nilai ekonomis yang tinggi. Konsumsi kopi dunia mencapai $70 \%$ berasal dari spesies kopi arabika dan $26 \%$ kopi robusta. Kopi berasal dari Afrika yaitu daerah pegunungan Ethiopia. Namun, kopi sendiri baru dikenal oleh masyarakat dunia setelah tanaman tersebut dikembangkan di luar daerah asalnya yaitu Yaman di bagian selatan Arab melalui para pedagang Arab (Rahardjo, 2012).

Pengolahan kopi itu mempunyai tujuan untuk meningkatkan produk olahan kopi sehingga layak untuk dikonsumsi dan memanfaatkan kopi agar memperoleh nilai jual yang tinggi dipasaran. Kabupaten Pati merupakan daerah dengan topografi daerah yang bervariasi dan sangat bagus untuk budidaya sektor pertanian, perkebunan, perikanan, peternakan dan kehutanan. Luas panen untuk tanaman perkebunan khususnya tanaman kopi di Kabupaten Pati pada tahun 2017 sebanyak 1.822,03 Ha dengan hasil produksi 1.187 .342 ton yang mengalami peningkatan dari tahun 2016 dengan luas panen 1.240,46 Ha dan hasil produksi 905.802,70 ton (Dinas Pertanian Kabupaten Pati, 2018).

Kecamatan Gembong merupakan salah satu daerah penghasil kopi di Kabupaten Pati, pada tahun 2015 menempati posisi pertama dari 21 kecamatan di Kabupaten Pati, dengan luas panen 1.126 ha dan hasil produksi 900,8 ton. Melimpahnya hasil produksi kopi menjadi salah satu faktor pendorong masyarakat Kecamatan Gembong untuk meningkatkan nilai jual kopi. Pengolahan kopi secara tepat akan mengurangi resiko terjadinya kerusakan, dapat memperpanjang umur simpannya, serta dapat meningkatkan nilai jualnya (Rukmana dan Yuniarsih, 2001). 
Kegiatan usaha pengolahan bubuk kopi di Kecamatan Gembong mengubah bentuk primer menjadi produk baru yang lebih tinggi nilai ekonomisnya. Proses pengolahan dapat memberikan pendapatan dan nilai tambah karena dikeluarkan biaya-biaya sehingga terbentuk harga baru yang lebih tinggi dan pendapatan yang lebih besar bila dibandingkan menjual kopi tanpa melalui proses pengolahan. Usaha pengolahan kopi perlu dikembangkan terutama di daerah sentra kopi seperti Kecamatan Gembong. Berdasarkan latar belakang tersebut maka perumusan masalah penelitian ini adalah berapa tingkat nilai tambah, pendapatan, titik impas (BEP) dan kelayakan usaha ditinjau dari R/C untuk pengolahan bubuk kopi hitam dan bubuk kopi hitam.

\section{BAHAN DAN METODE}

Metode dasar dalam penelitian ini adalah metode deskriptif. Pengambilan sampel dilakukan dengan cara teknik purposive sampling. Alasan utama pemilihan lokasi ini Kecamatan Gembong merupakan Kecamatan di Kabupaten Pati pada tahun 2017 memiliki luas tanam, produksi dan produktivitas kopi tertinggi yaitu seluas 1.126 ha dengan produksi 900,8 ton dan produktivitas sebesar 0,800 ton/ha. Populasi penelitian ini adalah anggota dari Kelompok Tani di Kecamatan Gembong Kabupaten Pati. Metode penentuan sampel pada penelitian ini adalah dengan menggunakan metode sensus. Responden penelitian ini sejumlah 5 pengrajin bubuk kopi hiitam dan 5 pengrajin bubuk kopi hijau.

Tabel 1. Analisis Nilai Tambah Metode Hayami

\begin{tabular}{|c|c|c|}
\hline No. & Variabel & Notasi \\
\hline 1 & Hasil Produksi (Kg/Minggu) & A \\
\hline 2 & Bahan Baku (Kg/Minggu) & B \\
\hline 3 & Tenaga Kerja (HOK/Minggu) & $\mathrm{C}$ \\
\hline 4 & Faktor Konversi (1/2) & $\mathrm{A} / \mathrm{B}=\mathrm{M}$ \\
\hline 5 & Koefisien Tenaga Kerja (3/2) & $\mathrm{C} / \mathrm{B}=\mathrm{N}$ \\
\hline 6 & Harga Produk Rata-Rata $(\mathrm{Rp} / \mathrm{Kg})$ & $\mathrm{D}$ \\
\hline 7 & Upah Rata-Rata (Rp/Minggu) & $\mathrm{E}$ \\
\hline 8 & Harga Bahan Baku (Rp/Kg) & $\mathrm{F}$ \\
\hline 9 & Sumbangan Input Lain $(\mathrm{Rp} / \mathrm{Kg})^{*}$ & G \\
\hline 10 & Nilai Produksi (4x6) (Rp/Kg) & $\mathrm{MXD}=\mathrm{K}$ \\
\hline \multirow[t]{2}{*}{11} & a. Nilai Tambah $(10-9-8)(\mathrm{Rp} / \mathrm{Kg})$ & $K-F-G=L$ \\
\hline & b. Ratio Nilai Tambah (11a/10) (\%) & $\mathrm{L} / \mathrm{K}=\mathrm{H}$ \\
\hline \multirow[t]{2}{*}{12} & a. Imbalan Tenaga Kerja $(5 \times 7)(\mathrm{Rp} / \mathrm{Kg})$ & $\mathrm{NXE}=\mathrm{P}$ \\
\hline & b. Bagian Tenaga Kerja (12a/11a) (\%) & $\mathrm{P} / \mathrm{L}=\mathrm{Q}$ \\
\hline \multirow[t]{2}{*}{13} & a. Keuntungan $(11 \mathrm{a}-12 \mathrm{a}) * *$ & $\mathrm{~L}-\mathrm{P}=\mathrm{R}$ \\
\hline & b. Tingkat Keuntungan (13a-11a) (\%) & $\mathrm{R} / \mathrm{L}=\mathrm{O}$ \\
\hline \multirow[t]{4}{*}{14} & Marjin (Rp/ Kg) & $\mathrm{Q}=\mathrm{J}-\mathrm{H}$ \\
\hline & a. Pendapatan Tenaga Kerja (\%) & $\mathrm{R} \%=\mathrm{M} / \mathrm{Q} \times 100 \%$ \\
\hline & b. Modal (sumbangan input lain) (\%) & $\mathrm{S} \%=\mathrm{I} / \mathrm{Q} \times 100 \%$ \\
\hline & c. Keuntungan Pengolahan (\%) & $\mathrm{T} \%=\mathrm{O} / \mathrm{Q} \times 100 \%$ \\
\hline
\end{tabular}

Sumber: Hayami, et, al., 1987 
Data yang digunakan dalam penelitian ini adalah data primer dan sekunder. Metode pengumpulan data diperoleh dari wawancara, observasi dan pencatatan. Analisis data yang digunakan dalam penelitian ini adalah analisis nilai tambah, analisis biaya usaha, pendapatan, titik impas (BEP) serta analisis kelayakan usaha ditinjau dari R/C.

\section{Analisis Nilai Tambah}

Kegiatan mengolah bahan baku menjadi berbagai macam bahan olahan mengakibatkan bertambahnya nilai komoditi tersebut. Guna melihat peningkatan nilai tambah pengolahan bahan baku serta menafsir balas jasa yang diterima para pelaku, maka dilakukan perhitungan nilai tambah. Metode yang digunakan untuk menghitung besarnya nilai tambah adalah metode Hayami dimana prosedur perhitungannya dapat dilihat pada Tabel 1.

Keterangan :

Ada tiga indikator rasio nilai tambah (Hubeis, 1997 dalam Ngamel, 2012):

1. Jika besarnya rasio nilai tambah $<15 \%$, maka nilai tambahnya rendah.

2. Jika besarnya rasio nilai tambah $15 \%-40 \%$, maka nilai tambahnya sedang.

3. Jika besarnya rasio nilai tambah $>40 \%$, maka nilai tambahnya tinggi.

\section{Biaya Penerimaan dan Pendapatan}

\section{a. Biaya Pengolahan Bubuk Kopi}

Biaya pengolahan bubuk kopi dihitung dengan menggunakan rumus sebagai berikut :

$$
\begin{aligned}
& \mathrm{TC}=\mathrm{FC}+\mathrm{VC} \\
& \text { Keterangan : } \\
& \mathrm{TC} \quad=\text { Biaya Total }(\text { total cost) } \\
& \mathrm{FC} \quad=\text { Biaya Tetap }(\text { fixed cost) } \\
& \mathrm{VC} \quad=\text { Biaya Tidak Tetap }(\text { variable cost) }
\end{aligned}
$$

b. Penerimaan Pengolahan Bubuk Kopi

Penerimaan dihitung dengan cara jumlah produksi dikalikan harga produksi dengan satuan rupiah.

$$
\text { Penerimaan }=\mathrm{Y} \text {. Py }
$$

Keterangan :

$\mathrm{Y} \quad=$ Jumlah Produksi $(\mathrm{Kg})$

Py = Harga Produksi (Rp)

\section{c. Pendapatan Pengolahan Bubuk Kopi}

Analisis pendapatan adalah selisih dari pendapatan kotor atau penerimaan dengan biaya mengusahakan. Analisis pendapatan pengolahan bubuk kopi hijau dan bubuk kopi hitam sistematis dapat ditulis :

Pendapatan $=$ Penerimaan - Biaya Total (Suratiyah, 2016).

\section{Titik Impas Break Event Point (BEP)}

Titik impas Break Event Point (BEP) pengolahan bubuk kopi hijau dan bubuk kopi. Secara sistematis dapat dihitung dengan menggunakan rumus sebagai berikut: 
a. BEP Produksi

Perhitungan BEP produksi dapat dilakukan dengan menggunakan rumus sebagai berikut :

BEP Produksi $=\frac{T C}{\text { Py }}$

Keterangan :

$\mathrm{TC}=$ Total Biaya $(\mathrm{Rp})$

Py = Harga Produksi (Rp) (Suratiyah, 2016)

b. BEP Harga

Perhitungan BEP harga dapat dilakukan dengan menggunakan rumus sebagai berikut :

BEP Harga $=\frac{T C}{\mathrm{Y}}$

Keterangan :

$\mathrm{TC}=$ Total Biaya $(\mathrm{Rp})$

Y = Produksi Total (Kg) (Suratiyah, 2016).

c. $\quad$ BEP Penerimaan $\left(\mathrm{BEP}_{(\mathrm{P})}\right)$

Adalah beberapa pendapatan kotor yang minimal harus diperoleh agar modal dapat kembali. Secara matematis dapat ditulis:

$\mathrm{BEP}_{(\mathrm{P})}=\frac{\text { Biaya Tetap }}{1-\left(\frac{\text { BiayaVariabel }}{\text { Penerimaan }}\right)}$

Dengan kriteria :

Penerimaan $>\mathrm{BEP}_{(\mathrm{P})}$ berarti usaha pengolahan bubuk kopi layak sedangkan penerimaan $<\mathrm{BEP}_{(\mathrm{P})}$ berarti usaha pengolahan bubuk kopi tidak layak. Jika penerimaan melebihi $\left(\mathrm{BEP}_{(\mathrm{P})}\right)$, maka usaha pengolahan kopi tersebut layak untuk diusahakan (Miller dan Roger, 2000).

\section{Analisis R/C}

Analisis kelayakan pengolahan bubuk kopi hijau dan bubuk kopi hitam berdasarkan $\mathrm{R} / \mathrm{C}$. R/C yaitu perbandingan antara penerimaan dengan total biaya per periode produksi satu minggu. Rumusnya adalah sebagai berikut :

$$
\mathrm{R} / \mathrm{C}=\mathrm{TR} / \mathrm{TC}
$$

\section{Keterangan :}

$\mathrm{R} \quad=$ Total Revenue (Penerimaan Usaha Pengolahan Bubuk Kopi)

$\mathrm{C}=$ Total Cost (Biaya Usaha Pengolahan Bubuk Kopi)

Kriteria:

R/C $<1$ : Pengolahan Bubuk Kopi Merugi

$\mathrm{R} / \mathrm{C}=1:$ Pengolahan Bubuk Kopi Impas

R/C > 1 : Pengolahan Bubuk Kopi Untung/Layak

$\mathrm{R} / \mathrm{C}$ ratio adalah singkatan dari revenue cost ratio, atau dikenal sebagai perbandingan atau nisbah antara penerimaan dan biaya. Makin besar nilai R/C ratio usaha pengolahan itu makin besar keuntungan yang diperoleh dari usaha tersebut (Soekartawi, 2016). 


\section{HASIL DAN PEMBAHASAN}

\section{Gambaran Umum Lokasi Penelitian}

Kondisi Kabupaten Pati secara geografis terletak antara $6^{\circ} 25^{\prime}-7^{\circ} 00^{\prime}$ lintang selatan dan antara $100^{\circ} 50^{\prime}-111^{\circ} 15^{\prime}$ bujur timur. Secara administratif letak geografis Kabupaten Pati berbatasan langsung dengan 6 Kabupaten/Kota. Berdasarkan data dari BPS tahun 2017, jumlah penduduk di Kecamatan Gembong sebanyak 44.389 jiwa. Jumlah penduduk di Kecamatan Gembong terdiri dari perempuan 22.236 jiwa dan jumlah penduduk laki-laki sejumlah 22.153 jiwa. Data jumlah penduduk berdasarkan dari jenis kelamin setiap desa yang terdiri dari 11 desa di Kecamatan Gembong. Penggunaan Lahan di Kecamatan Gembong sebagian besar digunakan untuk lahan pertanian. Lahan pertanian yang ada di Kecamatan tersebut terdiri dari lahan sawah, lahan tidak sawah dan bukan lahan pertanian. Luas wilayah tiap desa menurut lahan sawah dan lahan bukan sawah di Kecamatan Gembong. Lahan sawah sebesar 823 Ha sedangkan lahan tidak sawah sebanyak $4568 \mathrm{Ha}$ yang terdiri dari tegalan sebesar $3564 \mathrm{Ha}$ dan lahan perkebunan terdiri dari $1.004 \mathrm{Ha}$. Potensi tanaman perkebunan kopi tergolong luas. Kecamatan Gembong merupakan potensi kopi terbesar di Kabupaten Pati. Hal ini menunjukkan minat masyarakat di daerah tersebut yang memanfaatkan lahannya untuk sektor tanaman perkebunan yang dirasa lebih menjanjikan dibandingkan dengan sektor lainnya.

\section{Pengolahan Bubuk Kopi Robusta}

Kopi ose berasal dari buah kopi basah yang telah mengalami beberapa tingkat proses pengolahan. Pengolahan biji kopi biasanya terdapat limbah berupa kulit biji kopi, dalam hal ini petani kopi di Kecamatan Gembong memanfaatkan limbah tersebut sebagai pupuk organik untuk dipupuk ke pohon kopi di lahan budidaya. Pemupukan di lokasi tersebut menggunakan pupuk organik yang berasal dari kotoran hewan dan limbah dari pengolahan biji kopi sebab sebagian besar pemikiran petani sudah mengerti bahwasanya organik itu lebih sehat, dan kendala untuk pembelian pupuk kimia dirasa terlalu sulit prosedurnya sehingga petani memilih menggunakan pupuk organik.

\section{Pengolahan Bubuk Kopi Hitam}

a. Roasting/ Penyangraian

Kegiatan penyangrain ini dilakukan menggunakan alat yang bernama roaster. Proses penyangraian dilakukan selama 30 menit dengan suhu $150^{\circ} \mathrm{C}$ dilanjutkan dengan suhu $170^{\circ} \mathrm{C}$ selama 30 menit. Kemudian dilakukan pendinginan agar biji kopi yang telah disangrai tidak gosong dengan cara diangin-anginkan dan dibolak-balik menggunakan spatula.

b. Penggilingan

Penggilingan menggunakan alat yang bernama grinder. Hasil penggilingan biji kopi dibedakan menjadi : bubuk kasar, bubuk halus dan bubuk sangat halus. Pengolahan kopi di Kecamatan Gembong melakukan penggilingan yang menghasilkan bubuk kopi halus.

c. Pengemasan

Pengemasan atau yang biasa disebut juga dengan pembungkusan merupakan hal terpenting dalam memperpanjang umur simpan hasil pertanian. Label kemasan terdapat informasi mengenai nama produk, berat, dan no P-IRT. 


\section{Pengolahan Bubuk Kopi Hijau}

a. Roasting/ Penyangraian

Roasting merupakan proses penyangraian kopi ose yang tergantung pada waktu dan suhu yang ditandai dengan perubahan kimiawi yang signifikan. Proses penyangraian dilakukan selama 15 menit dengan suhu $75^{\circ} \mathrm{C}$, berbeda dengan pengolahan bubuk kopi hitam. Bubuk kopi hijau memerlukan waktu yang lebih singkat dan suhu yang lebih rendah untuk mensterilkan biji kopi agar tidak terkontaminasi dengan kotoran yang menempel di biji kopi.

b. Penggilingan

Penggilingan menggunakan alat yang bernama grinder. Hasil penggilingan biji kopi dibedakan menjadi : bubuk kasar, bubuk halus dan bubuk sangat halus. Pengolahan kopi di Kecamatan Gembong melalukan penggilingan yang menghasilkan bubuk kopi halus.

c. Pengemasan

Pengemasan atau yang biasa disebut juga dengan pembungkusan merupakan hal terpenting dalam memperpanjang umur simpan hasil pertanian. Label kemasan terdapat informasi mengenai nama produk, berat, dan no P-IRT.

\section{Karakteristik Responden}

Tabel 2. Karakteristik Responden berdasarkan Umur, Tingkat Pendidikan, Lama Usaha dan Sumber Modal Usaha Pengolahan Bubuk Kopi Hitam dan Bubuk Kopi Hijau di Kecamatan Gembong Kabupaten Pati.

\begin{tabular}{|c|c|c|c|}
\hline No & Uraian & Bubuk Kopi Hitam & Bubuk Kopi Hijau \\
\hline \multirow[t]{5}{*}{1} & Umur Responden (tahun) & & \\
\hline & a. $21-30$ & - & $2(40)$ \\
\hline & b. $31-40$ & $1(20)$ & $1(20)$ \\
\hline & c. $41-50$ & $4(80)$ & $2(40)$ \\
\hline & Jumlah & $5(100)$ & $5(100)$ \\
\hline \multirow[t]{6}{*}{2} & Tingkat Pendidikan (jiwa) & & \\
\hline & a. SD & - & $1(20)$ \\
\hline & b. SMP & - & - \\
\hline & c. SMA & $3(60)$ & $4(80)$ \\
\hline & d. S1 & $2(40)$ & - \\
\hline & Jumlah & $5(100)$ & $5(100)$ \\
\hline \multirow[t]{5}{*}{3} & Lama Usaha (tahun) & & \\
\hline & a. $1-2$ & $1(20)$ & $4(80)$ \\
\hline & b. $3-4$ & $2(40)$ & $1(20)$ \\
\hline & c. $>5$ & $2(40)$ & - \\
\hline & Jumlah & $5(100)$ & $5(100)$ \\
\hline \multirow[t]{4}{*}{4} & Sumber Modal (orang) & & \\
\hline & a. Modal Sendiri & - & - \\
\hline & b. Modal Pinjaman & $5(100)$ & $5(100)$ \\
\hline & Jumlah & $5(100)$ & $5(100)$ \\
\hline
\end{tabular}

Sumber : Analisis Data Primer, 2018. 
Tabel 3. Rata-Rata Analisis Nilai Tambah Usaha Pengolahan Bubuk Kopi Hitam Bubuk Kopi Hijau di Kecamatan Gembong Kabupaten Pati per Periode Produksi Satu Minggu.

\begin{tabular}{|c|c|c|c|c|}
\hline No & Variabel & Rumus & $\begin{array}{c}\text { Bubuk } \\
\text { Kopi } \\
\text { Hitam } \\
\end{array}$ & $\begin{array}{c}\text { Bubuk } \\
\text { Kopi } \\
\text { Hijau } \\
\end{array}$ \\
\hline $\mathbf{1}$ & Output(Kg/Minggu) & $\mathrm{A}$ & 12,48 & 6,84 \\
\hline 2 & Input (Kg/Minggu) & $\mathrm{B}$ & 15,60 & 7,60 \\
\hline 3 & $\begin{array}{l}\text { Tenaga kerja } \quad(\mathrm{HOK} / \\
\text { Minggu })\end{array}$ & $\mathrm{C}$ & 0,75 & 0,75 \\
\hline 4 & Faktor konversi & $\mathrm{D}=\mathrm{A} / \mathrm{B}$ & 0,80 & 0,90 \\
\hline 5 & $\begin{array}{l}\text { Koefisien } \\
(\mathrm{HOK} / \mathrm{kg})\end{array}$ Tenaga $\quad$ kerja & $\mathrm{E}=\mathrm{C} / \mathrm{B}$ & 0,06 & 0,10 \\
\hline 6 & Harga output (Rp/kg) & $\mathrm{F}$ & 104.000 & 215.000 \\
\hline 7 & $\begin{array}{l}\text { Upah Tenaga kerja } \\
(\mathrm{Rp} / \mathrm{HOK})\end{array}$ & $\mathrm{G}$ & 110.933 & 88.435 \\
\hline & $\begin{array}{l}\text { Pendapatan dan } \\
\text { Tambah }(\mathrm{Rp} / \mathrm{Kg})\end{array}$ & & & \\
\hline 8 & Harga bahan baku $(\mathrm{Rp} / \mathrm{Kg})$ & $\mathrm{H}$ & 23.000 & 70.000 \\
\hline 9 & Harga input lain $(\mathrm{Rp} / \mathrm{Kg})$ & $\mathrm{I}$ & 23.905 & 29.750 \\
\hline 10 & put $(\mathrm{Rp} / \mathrm{Kg})$ & $\mathrm{J}=\mathrm{D} \times \mathrm{F}$ & 83.200 & 193.500 \\
\hline 11 & Nilai tambah $(\mathrm{Rp} / \mathrm{Kg})$ & $\mathrm{K}=\mathrm{J}-\mathrm{H}-\mathrm{I}$ & 36.295 & 93.750 \\
\hline & lai Tambah (\%) & $\begin{array}{l}\mathrm{L} \%=\mathrm{K} / \mathrm{J} \times \\
100 \%\end{array}$ & 43,52 & 48,06 \\
\hline 12 & $\begin{array}{l}\text { Pendapatan Tenaga kerja } \\
(\mathrm{Rp} / \mathrm{Kg})\end{array}$ & $\mathrm{M}=\mathrm{E} \times \mathrm{G}$ & 6.410 & 8.850 \\
\hline & naga kerja (\%) & $\begin{array}{l}\mathrm{N} \%=\mathrm{M} / \mathrm{K} \times \\
100 \%\end{array}$ & 17,68 & 9,72 \\
\hline 13 & Keuntungan (Rp/Kg) & $\mathrm{O}=\mathrm{K}-\mathrm{M}$ & 29.885 & 84.900 \\
\hline & Tingkat keuntungan $(\%)$ & $\begin{array}{l}\mathrm{P} \%=\mathrm{O} / \mathrm{J} \times \\
100 \%\end{array}$ & 35,76 & 43,45 \\
\hline & $\begin{array}{lll}\text { Balas } & \text { Jasa } & \text { Faktor } \\
\text { Produksi } & & \\
\end{array}$ & & & \\
\hline 14 & Marjin $(\mathrm{Rp} / \mathrm{Kg})$ & $\mathrm{Q}=\mathrm{J}-\mathrm{H}$ & 60.200 & 123.500 \\
\hline & kerja & $\begin{array}{l}\mathrm{R} \%=\mathrm{M} / \mathrm{Q} \times \\
100 \%\end{array}$ & 10,76 & 7,29 \\
\hline & $\begin{array}{l}\text { b. Modal (sumbangan input } \\
\text { lain) }(\%)\end{array}$ & $\begin{array}{l}\mathrm{S} \%=\mathrm{I} / \mathrm{Q} \times \\
100 \%\end{array}$ & 39,84 & 24,49 \\
\hline & c. Keuntungan $(\%)$ & $\begin{array}{l}\mathrm{T} \%=\mathrm{O} / \mathrm{Q} \times \\
100 \%\end{array}$ & 49,40 & 68,21 \\
\hline
\end{tabular}

Sumber : Analisis Data Primer, 2018.

Berdasarkan hasil penelitian sebanyak 5 pengrajin bubuk kopi hitam dan 5 pengrajin bubuk kopi hijau yang telah dilakukan, diketahui profil responden yang dapat digunakan sebagai data pendukung pembahasan dalam penelitian ini meliputi beberapa aspek yaitu umur responden, luas lahan, lama usaha dan tingkat 
pendidikan. Hasil penelitian yang dilakukan diperoleh data dapat dilihat pada Tabel 2.

Analisis data merupakan suatu proses atau upaya pengolahan data menjadi sebuah informasi baru agar karakteristik data tersebut menjadi lebih mudah dimengerti dan berguna untuk solusi suatu permasalahan, khususnya yang berhubungan dengan penelitian. Selain itu data dapat digunakan untuk mengidentifikasi ada tidaknya suatu permasalahan.

\section{Analisis Nilai Tambah}

Analisis nilai tambah usaha pengolahan bubuk kopi hitam dan bubuk kopi hijau dilakukan guna mengetahui besarnya nilai yang ditambahkan pada bahan baku yang digunakan dalam memproduksi bubuk kopi. Hasil perhitungan analisis nilai tambah usaha pengolahan bubuk kopi hitam dan bubuk kopi hijau di Kecamatan Gembong Kabupaten Pati dapat dilihat pada Tabel 3.

Tabel 3. menunjukkan bahwa perhitungan analisis nilai tambah selama satu minggu proses produksi, diketahui bahwa rata-rata penggunaan bahan baku dalam usaha pengolahan bubuk kopi hitam dan bubuk kopi hijau di Kecamatan Gembong Kabupaten Pati untuk bubuk kopi hitam menggunakan bahan baku sebanyak 15,6 kg kopi ose dengan harga Rp. 23.000/kg, menghasilkan 12,48 kg bubuk kopi hitam, dengan rata-rata harga jual Rp 104.000/kg bubuk kopi hitam. Sementara bubuk kopi hijau menggunakan bahan baku sebanyak 7,6 kg kopi ose dengan harga Rp. 70.000/kg, menghasilkan 6,84 kg bubuk kopi hijau, dengan rata-rata harga jual $\mathrm{Rp} 215.000 / \mathrm{kg}$ bubuk kopi hijau.

Nilai faktor konversi pada usaha pengolahan bubuk kopi di Kecamatan Gembong bubuk kopi hitam yaitu sebesar 0,80 sedangkan bubuk kopi hijau sebesar 0,90 didapat dari pembagian antara output yang dihasilkan bubuk kopi hitam sebesar 12,48 Kg dengan input yang digunakan sebesar 15,6 Kg bubuk kopi hitam sedangkan didapat dari pembagian antara output yang dihasilkan bubuk kopi hijau sebesar 6,84 Kg dengan input yang digunakan sebesar 7,6 bubuk kopi hijau. Nilai koefisien tenaga kerja pada usaha pengolahan bubuk kopi hitam sebesar 0,06 dan bubuk kopi hijau sebesar 0,10 di Kecamatan Gembong.

Nilai tambah yang dihasilkan oleh pengolah bubuk kopi hitam di Kecamatan Gembong Kabupaten Pati sebesar Rp. 36.295/kg artinya untuk setiap satu kilogram bahan baku kopi hitam memberikan nilai tambah sebesar Rp. 36.295/Kg yang di dapat dari hasil selisih antara nilai produk $\mathrm{Rp} 83.200 / \mathrm{Kg}$ dengan sumbangan input lain $\mathrm{Rp} 23.905 / \mathrm{Kg}$ dan dengan harga bahan baku $\mathrm{Rp}$ $23.000 / \mathrm{Kg}$ dengan ratio $43,52 \%$ dari nilai produk sedangkan nilai tambah pengolahan bubuk kopi hijau sebesar Rp. 93.500/Kg artinya untuk setiap satu kilogram bahan baku kopi hijau memberikan nilai tambah sebesar Rp 93.500/Kg yang di dapat dari hasil selisih antara nilai produk $\mathrm{Rp} 193.500 / \mathrm{Kg}$ dengan sumbangan input lain Rp 29.750/Kg dan dengan harga bahan baku Rp 70.000/Kg dengan ratio $48,06 \%$ dari nilai produk.

Balas jasa faktor produksi pengolahan bubuk kopi hitam marjin diperoleh Rp. 60.200/Kg, margin tenaga kerja 10,76\% atau Rp.6.479, marjin modal 39,84\% atau Rp. 23.981 dan marjin keuntungan $49,40 \%$ atau 29.740. Pengolahan bubuk kopi hijau marjin diperoleh Rp. $123.500 / \mathrm{Kg}$, margin tenaga kerja 7,29\% atau Rp. 
9.009, marjin modal 24,49\% atau Rp. 30.247 dan marjin keuntungan 68,21\% atau Rp. 84.244. Margin untuk sumbangan input lain merupakan bagian terbesar bila dibandingkan dengan pendapatan kerja dan keuntungan perusahaan. Hasil analisis nilai tambah dapat dilihat bahwa usaha pengolahan bubuk kopi hitam dan bubuk kopi hijau dapat menghasilkan keuntungan 49,40\% dan 68,21\% dari nilai produk sehingga usaha pengolahan bubuk kopi layak untuk dikembangkan.

\section{Biaya Usaha Pengolahan Bubuk Kopi Hijau dan Bubuk Kopi Hitam}

Biaya dalam penelitian ini adalah seluruh biaya yang dikeluarkan selama satu periode produksi yaitu satu minggu proses produksi. Berdasarkan hasil penelitian yang dilakukan diperoleh data Tabel 4 .

Tabel 4. Rata - Rata Biaya Produksi Pengolahan Bubuk Kopi Hitam dan Bubuk Kopi Hijau per Periode Produksi Satu Minggu.

\begin{tabular}{lrr}
\hline \multicolumn{1}{c}{ Variabel } & Bubuk Kopi Hitam & Bubuk Kopi Hijau \\
\hline a. Biaya tetap & & \\
- Penyusutan Alat (Rp) & 73.428 & 70.259 \\
- Bunga Modal Investasi & 152.872 & 145.488 \\
\hline Jumlah biaya tetap (a) & $\mathbf{2 2 6 . 3 0 0}$ & $\mathbf{2 1 5 . 7 4 7}$ \\
\hline b. Biaya variabel & & \\
- Bahan Baku (Kopi Ose) & 358.800 & 532.000 \\
- Biaya Bahan Bakar & 39.000 & 14.800 \\
- Biaya Air dan Listrik & 29.200 & 16.600 \\
- Tenaga Kerja Luar Keluarga & 112.800 & 58.320 \\
- Tenaga Kerja Dalam & & \\
Keluarga & 30.000 & 22.500 \\
- Kemasan & 322.240 & 196.740 \\
\hline Jumlah biaya variabel (b) & $\mathbf{9 0 7 . 0 4 0}$ & $\mathbf{8 4 0 . 9 6 0}$ \\
\hline Total biaya (a+b) & $\mathbf{1 . 1 3 3 . 3 4 0}$ & $\mathbf{1 . 0 5 6 . 7 0 7}$ \\
\hline Sumber : Anasis Data Primer
\end{tabular}

Sumber : Analisis Data Primer, 2018.

Berdasarkan Tabel 4. diketahui bahwa total biaya produksi pengolahan bubuk kopi hitam adalah Rp. 1.133.340/PP Satu Minggu dan pengolahan bubuk kopi hijau adalah Rp. 1.056.000/PP Satu Minggu. Modal nvestasi adalah pengeluaran penanaman modal yang dikeluarkan oleh pengusaha untuk membeli barang-barang modal dan perlengkapan produksi dalam memproduksi bubuk kopi hitam dan bubuk kopi hijau. Hasil tersebut menunjukkan perbedaan biaya terbesar terletak pada jumlah bahan baku yang digunakan, untuk pembelian bahan baku kopi ose dalam pengolahan kopi hitam sebesar Rp. 358.800/Kg sedangkan pembelian bahan baku kopi ose dalam pengolahan kopi hijau sebesar Rp. $532.000 / \mathrm{Kg}$.

\section{Penerimaan Usaha Pengolahan Bubuk Kopi Hitam dan Bubuk Kopi Hijau}

Penerimaan dihitung dari total produksi dikalikan harga produk dengan satuan rupiah. Berdasarkan hasil penelitian yang dilakukan diperoleh data seperti pada Tabel 5. 
Tabel 5. Rata - Rata Produksi dan Penerimaan Usaha Pengolahan Bubuk Kopi Hitam dan Bubuk Kopi Hijau di Kecamatan Gembong Kabupaten Pati per Periode Produksi Satu Minggu.

\begin{tabular}{clrr}
\hline No & Unsur Penerimaan & Bubuk Kopi Hitam & Bubuk Kopi Hijau \\
\hline 1 & Total Produksi $(\mathrm{Kg})$ & 12,48 & 6,84 \\
2 & Harga Produk $(\mathrm{Rp} / \mathrm{Kg})$ & 104.000 & 215.000 \\
\hline & Jumlah $(\mathrm{Rp})$ & 1.297 .920 & 1.470 .600 \\
\hline
\end{tabular}

Sumber : Analisis Data Primer, 2018.

Berdasarkan Tabel 5. diketahui bahwa produksi bubuk kopi hitam sebesar $12,48 \mathrm{Kg}$ sedangkan produksi bubuk kopi hijau sebesar $6,84 \mathrm{Kg}$, dari hasil tersebut terdapat perbedaan karena di sebabkan oleh jumlah bahan baku yang digunakan serta penyusutan produk yang berbeda antara kopi bubuk hitam dan kopi bubuk hijau.

Harga penjualan kopi bubuk hitam sebesar Rp. 104.000/Kg sedangkan penjualan bubuk kopi hijau sebesar Rp. $215.000 / \mathrm{Kg}$, harga jual bubuk kopi hijau dapat lebih mahal dibandingkan dengan bubuk kopi hitam karena terjadi perbedaan proses produksi sehingga mengakibatkan perbedaan harga. Dapat diketahui penerimaan bubuk kopi hitam sebesar Rp. 1.297.920/PP Satu Minggu dan penerimaan bubuk kopi hijau sebesar Rp. 1.470.600/PP Satu Minggu.

\section{Pendapatan Pengolahan Bubuk Kopi Hitam dan Bubuk Kopi Hijau}

Analisis pendapatan dapat diperoleh dari selisih dari pendapatan kotor atau penerimaan dengan biaya produksi tanpa memasukkan biaya penyusutan alat dan biaya tenaga kerja dalam keluarga. Berdasarkan hasil penelitian yang dilakukan diperoleh data Tabel 6.

Tabel 6. Rata - Rata Pendapatan Usaha Pengolahan Bubuk Kopi Hitam dan Bubuk Kopi Hijau per Periode Produksi Satu Minggu.

\begin{tabular}{clcr}
\hline No & \multicolumn{1}{c}{ Unsur } & Bubuk Kopi & \multicolumn{2}{c}{ Bubuk Kopi Hijau } \\
& & Hitam & 1.470 .600 \\
1 & Total Penerimaan (Rp) & 1.297 .920 & 890.287 \\
\hline 2 & Total Biaya Eksplisit (Rp) & 937.328 & 580.313 \\
\hline
\end{tabular}

Sumber: Analisis data primer 2018.

Berdasarkan Tabel 6. diketahui bahwa pendapatan usaha pengolahan jika yang dihitung dari total biaya eksplisit. Hasil perhitungan pendapatan jika di kurangi dengan biaya ekplisit pengolahan bubuk kopi hitam sebesar Rp. 360.592/PP Satu Minggu dan pengolahan bubuk kopi hijau sebesar Rp. 580.313/PP Satu Minggu. Pendapatan tersebut dipengaruhi oleh produksi bubuk kopi dan harga jual produk bubuk kopi.

\section{Titik Impas (BEP)}

Analisis kelayakan usaha pengolahan bubuk kopi hitam dan bubuk kopi hijau berdasarkan analisis Break Even Point (BEP). Break Even Point (BEP) adalah titik impas dimana pengrajin akan menerima pendapatan yang sama 
dengan total biaya produksi yang dikeluarkan untuk usaha pengolahannya. BEP yang dihitung dalam penelitian ini yaitu BEP Produksi (Kg), BEP Harga ( $\mathrm{Rp} / \mathrm{Kg}$ ), dan BEP Penerimaan (Rp/PP Satu Minggu) dengan hasil sebagai berikut:

1. BEP Produksi $(\mathrm{Kg})$

BEP Produksi dapat dihitung dengan rumus total biaya produksi dibagi dengan harga produksi. Berdasarkan hasil penelitian yang dilakukan diperoleh data Tabel 7.

Tabel 7. Rata - Rata Analisis BEP Produksi Usaha Pengolahan Bubuk Kopi Hitam dan Bubuk Kopi Hijau per Periode Produksi Satu Minggu.

\begin{tabular}{clcc}
\hline No & \multicolumn{1}{c}{ Unsur } & $\begin{array}{c}\text { Bubuk Kopi } \\
\text { Hitam }\end{array}$ & $\begin{array}{c}\text { Bubuk Kopi } \\
\text { Hijau }\end{array}$ \\
\hline 1 & Total Biaya Produksi $(\mathrm{Rp})$ & 1.133 .340 & 1.056 .707 \\
2 & Total Produksi $(\mathrm{Kg})$ & 12,48 & 6,84 \\
3 & BEP $_{(\mathrm{Q})}(\mathrm{Kg})$ & 10,90 & 4,91 \\
\hline
\end{tabular}

Sumber : Analisis data primer 2018.

Berdasarkan Tabel 7. diketahui bahwa hasil titik impas usahatani bubuk kopi hitam dan bubuk kopi hijau diperoleh BEP produksi 10,90 Kg dan 4,91 Kg yang artinya produksi minimal yang harus dicapai agar total biaya produksi yang dikeluarkan dapat kembali. Usaha pengolahan bubuk kopi hitam dan bubuk kopi hijau sudah melebihi $\mathrm{BEP}_{(\mathrm{Q})}$ yaitu $12,48 \mathrm{Kg}$ dan $6,84 \mathrm{Kg}$, sehingga didapatkan usaha pengolahan bubuk kopi hitam dan bubuk kopi hijau menguntungkan dan layak diusahakan.

2. BEP Harga $(\mathrm{Rp} / \mathrm{Kg})$

BEP Harga dapat dihitung dengan rumus total biaya dibagi dengan produksi total. Berdasarkan hasil penelitian yang dilakukan diperoleh data Tabel 8.

Tabel 8. Rata - Rata Analisis BEP Harga Pengolahan Bubuk Kopi Hitam dan Bubuk Kopi Hijau per Periode Produksi Satu Minggu.

\begin{tabular}{|c|c|c|c|c|}
\hline No & Unsu & & Bubuk Kopi Hitam & $\begin{array}{c}\text { Bubuk Kopi } \\
\text { Hijau }\end{array}$ \\
\hline 1 & Total Biaya Produ & (Rp) & 1.133 .340 & 1.056 .707 \\
\hline 2 & $\begin{array}{l}\text { Harga } \\
(\mathrm{Rp} / \mathrm{Kg})\end{array}$ & Kopi & 104.000 & 215.000 \\
\hline 3 & BEP Harga (Rp) & & 90.813 & 154.489 \\
\hline
\end{tabular}

Sumber: Analisis data primer 2018.

Berdasarkan Tabel 8. diketahui bahwa hasil titik impas usaha pengolahan bubuk kopi hitam dan bubuk kopi hijau diperoleh BEP harga sebesar Rp. 90.813/Kg dan Rp. 154.489/Kg artinya harga terendah yang harus dicapai agar usaha pengolahan mengalami titik impas. Hasil penelitian kelayakan usaha pengolahan bubuk kopi hitam dan bubuk kopi hijau sudah berada diatas harga BEP yaitu Rp. $104.000 / \mathrm{Kg}$ dan Rp. $215.000 / \mathrm{Kg}$, 
sehingga didapatkan usaha pengolahan bubuk kopi hitam dan bubuk kopi hijau menguntungkan dan layak dikembangkan setelah melihat dari BEP.

3. BEP Penerimaan (Rp/ PP Satu Minggu)

BEP penerimaan dapat dihitung dengan rumus biaya tetap dibagi dengan satu dikalikan biaya variabel dibagi penerimaan. Berdasarkan hasil penelitian yang dilakukan, diperoleh data pada Tabel 9.

Tabel 9. Rata-Rata Analisis BEP Penerimaan Pengolahan Bubuk Kopi Hitam dan Bubuk Kopi Hijau per Periode Produksi Satu Minggu.

\begin{tabular}{|c|c|c|c|}
\hline No & Unsur & $\begin{array}{c}\text { Bubuk Kopi } \\
\text { Hitam }\end{array}$ & $\begin{array}{c}\text { Bubuk Kopi } \\
\text { Hijau }\end{array}$ \\
\hline 1 & P Satu Mis & 1.297 .920 & 1.470 .600 \\
\hline 2 & BEP Penerimaan (Rp) & 751.431 & 503.903 \\
\hline
\end{tabular}

Sumber : Analisis data primer 2018.

Berdasarkan Tabel 9. diketahui bahwa hasil titik impas usaha pengolahan bubuk kopi hitam dan bubuk kopi hijau diperoleh BEP penerimaan sebesar Rp. 751.431/PP Satu Minggu dan Rp. 503.903/PP Satu Minggu artinya harga terendah yang harus dicapai agar usaha pengolahan mengalami titik impas. Hasil penelitian kelayakan usaha pengolahan bubuk kopi hitam dan bubuk kopi hijau sudah berada diatas penerimaan BEP yaitu Rp. 1.297.920/PP Satu Minggu dan Rp. 1.470.600/PP Satu Minggu, sehingga didapatkan usaha pengolahan bubuk kopi hitam dan bubuk kopi hijau menguntungkan dan layak dikembangkan setelah melihat dari BEP Penerimaan (Rp/PP Satu Minggu).

\section{Analisis R/C}

Analisis kelayakan usaha pengolahan bubuk kopi hitam dan bubuk kopi hijau berdasarkan analisis Revenue Cost Ratio (R/C). R/C dapat dihitung dengan penerimaan dibagi dengan total biaya produksi. Berdasarkan hasil penelitian yang dilakukan diperoleh data Tabel 10.

Tabel 10. Rata - Rata Analisis R/C Usaha Pengolahan Bubuk Kopi Hitam dan Bubuk Kopi Hijau per Periode Produksi Satu Minggu.

\begin{tabular}{clcc}
\hline No & \multicolumn{1}{c}{ Unsur } & Bubuk Kopi Hitam & Bubuk Kopi Hijau \\
\hline 1 & Total Biaya Produksi (Rp) & 937.328 & 890.287 \\
2 & Penerimaan (Rp) & 1.297 .920 & 1.470 .600 \\
3 & R/C Ratio & 1,38 & 1,65 \\
\hline
\end{tabular}

Sumber : Analisis data primer 2018.

Berdasarkan Tabel 10. diketahui bahwa R/C usaha pengolahan bubuk kopi hitam sebesar 1,38 dan R/C usaha pengolahan bubuk kopi hijau sebesar 1,65 yang artinya setiap penggunaan input sebesar 1 akan memberikan keuntungan pada bubuk kopi hitam 1,38 dan bubuk kopi hijau 1,65. R/C keduanya $>1$ sehingga usaha pengolahan bubuk kopi hitam dan bubuk kopi hijau menguntungkan dan layak diusahakan. 


\section{KESIMPULAN}

1. Besarnya nilai tambah bubuk kopi hitam sebesar Rp. 36.295/Kg dengan rasio 43,52\% dari nilai produk. sedangkan bubuk kopi hijau sebesar Rp. 93.750/Kg dengan rasio 48,06\% dari nilai produk sehingga nilai tambah pengolahan bubuk kopi tergolong memiliki nilai tambah yang tinggi karena lebih dari $40 \%$.

2. Rata - rata penerimaan sebesar Rp. 1.297.920/PP Satu Minggu untuk pengolahan bubuk kopi hitam dan usaha pengolahan bubuk kopi hijau sebesar Rp. 1.470.600/PP Satu Minggu, dengan rata - rata total biaya produksi bubuk kopi hitam sebesar Rp. 1.133.340/PP Satu Minggu dan biaya produksi bubuk kopi hitam sebesar Rp. 1.056.707/PP Satu Minggu sehingga diperoleh rata - rata pendapatan usaha pengolahan bubuk kopi hitam sebesar Rp. 360.592/PP Satu Minggu dan usaha pengolahan bubuk kopi hijau sebesar Rp. 580.313/PP Satu Minggu.

3. Pengolahan kopi bubuk hitam, diperoleh nilai BEP Produksi $=10,90 \mathrm{~kg}$ (riil $=12,48 \mathrm{Kg}$ ), BEP Harga $=$ Rp. 90.813/Kg (riil = Rp. 104.000/Kg), BEP Penerimaan $=$ Rp. 751.431/PP Satu Minggu (riil $=$ Rp. 1.297.920/PP Satu Minggu) sedangkan kelayakan usaha pengolahan bubuk kopi hijau sebesar nilai BEP Produksi = 4,91 Kg (riil = 6,84 Kg), BEP Harga = Rp. 154.489/Kg $($ riil $=$ Rp. $215.000 / \mathrm{Kg})$, BEP Penerimaan $=$ Rp. 503.592/PP Satu Minggu (riil = Rp. 1.470.600/PP Satu Minggu).

4. Nilai R/C usaha pengolahan bubuk kopi hitam sebesar 1,38 sedangkan usaha pengolahan bubuk kopi hijau sebesar 1,65.

\section{SARAN}

1. Pengrajin dapat meningkatkan pendapatan yang diperoleh dalam usaha pengolahan kopi Robusta dengan cara lebih efisiensi dalam penggunaan biaya yang dikeluarkan dalam proses pengolahan.

2. Pengrajin lebih baik melakukan usaha pengolahan bubuk kopi hijau dibandingkan pengolahan bubuk kopi hitam jika dilihat dari besarnya nilai $\mathrm{R} / \mathrm{C}$, akan tetapi permintaan bubuk kopi hijau masih rendah.

3. Perlu adanya pengenalan terhadap masyarakat akan manfaat dan kelebihan kopi bubuk hijau untuk kesehatan manusia, sehingga permintaan terhadap bubuk kopi hijau meningkat dibandingkan dengan bubuk kopi hitam dengan harapan keuntungan yang dihasilkan oleh pengrajin pengolahan bubuk kopi semakin tinggi.

4. Pengrajin bubuk kopi seharusnya lebih berinovasi dalam pengolahan bubuk kopi sehingga muncul produk baru yang akan meningkatkan daya tarik konsumen terhadap produk kopi tersebut.

\section{DAFTAR PUSTAKA}

Firdaus, M. 2009. Manajemen Agribisnis. Jakarta : Bumi Aksara. 
Hayami dan Kikuchi. 1987. Dilema Ekonomi Desa Suatu Pendekatan Ekonomi terhadap Perubahan Kelembagaan di Asia, Editor: Gunawan Wiradi. Jakarta : Yayasan Obor Indonesia.

Hubeis, M. 1997. Menuju Industri Kecil Profesional di Era Globalisasi Melalui Pemberdayaan Manajemen Industri. Orasi Ilmiah Guru Tetap Ilmu Manajemen Industri. Fakultas Pertanian. Institut Pertanian Bogor.

Ngamel, Anna Kartika. 2012. Analisis Manajemen Pengadaan Bahan Baku Nilai Tambah dan Strategi Pemasaran Pisang Bolen di Bandar Lampung. Skripsi. Fakultas Pertanian. Bandar Lampung : Universitas Lampung.

Nazir. 2014. Metode Penelitian Sosial. Edisi Kesembilan. Jakarta : Erlangga.

Rahardjo, Pudji. 2012. Panduan Budidaya dan Pengolahan Kopi Arabika dan Robusta. Jakarta : Penebar Swadaya.

Ria, JH., dan Djumidi. 2000. Inventaris Tanaman Obat Indonesia. Jakarta: Departemen Kesehatan dan Kesejahteraan Sosial Republik Indonesia Badan Penelitian dan Pengembangan Kesehatan.

Soekartawi. 2016. Analisis Usaha Tani. Jakarta : UI-Press.

Suratiyah, K. 2016. Ilmu Usahatani. Jakarta : Penebar Swadaya. 